$\begin{array}{ll} & \text { Etnográfica } \\ \text { etnográfica } & \text { Revista do Centro em Rede de Investigação em }\end{array}$

Antropologia

vol. 11 (2) | 2007

Vol. 11 (2)

\title{
Jim Butcher, The Moralization of Tourism, Sun, Sand and... Saving the World
}

\section{Maria Cardeira da Silva}

\section{OpenEdition \\ Journals}

\section{Edição electrónica}

URL: https://journals.openedition.org/etnografica/2061

DOI: 10.4000/etnografica.2061

ISSN: 2182-2891

\section{Editora}

Centro em Rede de Investigação em Antropologia

\section{Edição impressa}

Data de publição: 1 novembro 2007

Paginação: 491-494

ISBN: 0873-6561; E-ISBN 2182-2891

ISSN: 0873-6561

\section{Refêrencia eletrónica}

Maria Cardeira da Silva, «Jim Butcher, The Moralization of Tourism, Sun, Sand and... Saving the World», Etnográfica [Online], vol. 11 (2) | 2007, posto online no dia 27 setembro 2012, consultado o 11 fevereiro 2022. URL: http://journals.openedition.org/etnografica/2061 ; DOI: https://doi.org/10.4000/ etnografica.2061

Este documento foi criado de forma automática no dia 11 fevereiro 2022.

\section{(i) (8)}

Etnográfica is licensed under a Creative Commons Attribution-NonCommercial 4.0 International License. 


\title{
Jim Butcher, The Moralization of Tourism, Sun, Sand and... Saving the World
}

\author{
Maria Cardeira da Silva
}

\section{REFERÊNCIA}

Jim Butcher, The Moralization of Tourism, Sun, Sand and... Saving the World, Londres e Nova Iorque, Routledge, Coll. Contemporary Geographies of Leisure, Tourism and Mobility, 2003.

1 Este é um livro virulento contra a alegada moralização contemporânea do turismo. (Do autor é apenas dito que lecciona no University College da Canterbury Christ Church em Kent, ficamos sem saber que disciplina, mas, pelo que se segue, não é decididamente antropologia). $\mathrm{Na}$ introdução escamoteia-se o facto de a argumentação não ser sustentada pelo "being there»"com a clássica citação "nothing human is foreign to me". É fácil esperar que se siga o desfiar do velho rosário contra o relativismo cultural que, como aqui se sustenta, está na base do novo turismo moral que impede os turistas de gozarem descontraidamente o seu tempo de lazer sem experimentarem sentimentos de culpa induzidos, em grande parte, pelos antropólogos. Na verdade, a antropologia aparece aqui como fazendo parte desse complot ou agenda empenhada em estragar o gozo dos turistas de massa - transformando-o numa missão - e impedir o desenvolvimento das populações visitadas (Butcher problematiza a noção de desenvolvimento sustentado, mas não a de desenvolvimento). Esta é a leitura irritada que se pode fazer da obra. Mas esqueçamos, por um momento, as críticas a que já nos vimos habituando e a visão fragmentada e distorcida da antropologia para reter algumas questões que, apesar de tudo, merecem atenção.

Do ponto de vista formal a obra é eficaz, com capítulos emoldurados por uma introdução e uma conclusão que explicitam e retomam argumentos que se reforçam e 
demasiadas vezes se repetem, criando a ilusão de que são óbvios. No primeiro define-se o que é o novo turismo moral (NTM) e resume-se a argumentação transversal dos seguintes. Logo aqui se evidencia a fragilidade do livro que adere, ingenuamente, à própria categorização que critica: o NTM assume aqui a reificação e essencialização de todas as formas críticas ao turismo de massa (contra o qual se define), sem ter em conta as formas e motivações diversificadas que lhes possam presidir. 0 maniqueísmo cria as suas próprias armadilhas. No segundo capítulo, a principal alegação é a de que, embora a massificação do turismo tenha sido desde sempre sujeita a críticas - a resenha histórica é breve mas interessante, repescando-se as críticas a Thomas cook e reforçando-se os argumentos das suas respostas, enfatizando-se a justiça social da democratização progressiva do lazer - hoje ele é sujeito a uma moralização que o desvirtua, colocando todas as suas formas (mesmo as mais insuspeitas como o ecoturismo, ou o turismo de gap year) sob escrutínio. Logo aqui Butcher fornece uma pista importante para a multiplicação das novas formas de turismo: de facto, as franjas alternativas e críticas ao turismo de massas sempre existiram, mas só agora elas são comercializadas. Na verdade, muito se explica pela segmentação dos mercados à qual responde, também, a lógica contemporânea do mercado turístico. Esse ponto é, no entanto, negligenciado por Butcher em favor do argumento de um princípio quase conspirativo - de correcção política - do NTM.

3 No terceiro capítulo, talvez o mais interessante, explora-se a ideia de fragilidade, e sua capacidade atractiva, dos destinos turísticos preferenciais do NTM. No quarto critica-se o pressuposto da liberdade pessoal associada às formas contemporâneas de turismo moral. No quinto desconstrói-se a noção de cultura que lhe é, alegadamente, inerente. No sexto denuncia-se a camuflagem das diferenças sociais e económicas pela "obcessão" pelas diferenças culturais; e no sétimo responsabiliza-se o cinismo de um altruísmo de classe média pelo bloqueio à economia transformativa.

4 Ao apresentar-se o novo turismo moral como categoria reificada e essencialista é fácil comparar o discurso e postura dos seus paladinos elitistas à antipatia ecuménica pelo turismo propalada pela Igreja ou por Franco (e, embora Salazar não venha mencionado, o desconcerto britânico snob face ao avassalamento turístico do Algarve é registado na página 25). Daí à associação das noç̃oes preservacionistas da cultura (como culturas) que se acusam no NTM com o Romantismo, e mais acutilantemente com o doutrinas racistas de Gobineau e Knox (p. 91), vai um passo, e todas as preocupações ecológicas, ambientalistas e com o respeito pela diferença cultural podem, então, impunemente passar a ter-se como reaccionárias. Butcher decididamente desconhece toda a discussão antropológica referente à cultura apesar do aparato que assumiu a partir dos anos 80 .

5 É verdade que muitas das abordagens críticas ao turismo de massa - logo, para Butcher, automaticamente do NTM - tomam a mudança como uma variável exógena em relação à cultura, mas já muitos antropólogos o denunciaram (como Eriksen - para citar apenas um - ao referir-se à concepção de cultura da UNESCO). ${ }^{1}$ É também verdade que essa prevalência tem afectado a linguagem sociológica do turismo e os indicadores maltusianos de "capacidade de carga" acentuam, como diz o autor, a ideia de fragilidade e o impulso de salvação inerentes às novas formas e retóricas do turismo mas, definitivamente, não implícitas à antropologia que, ao contrário do que Butcher aqui faz, se preocupa em dar a voz todos os intervenientes nos processos culturais e, consequentemente, também, às populações visitadas. Se Butcher ouvisse essas vozes de certo entenderia que, embora, como ele diz (seguindo muitos antropólogos) as 
diferenças culturais e a fragilidade ambiental sirvam frequentemente para camuflar outras diferenças (económicas, sociais e políticas), elas não devem, nem podem, ser violadas e desbaratadas sobretudo quando são tidas, pelas próprias populações envolvidas, como um recurso (muitas vezes um dos poucos recursos) que permite mitigar essas diferenças.

6 Na realidade, a argumentação de Butcher repete, em muitos pontos, alguns textos da antropologia do turismo, mesmo quando se dedica a criticar as posições de alguns cientistas sociais que vêem no turismo uma forma de neocolonialismo (Nash, Ash e Turner, aos quais podíamos ainda somar, sem medo, outros como Young, de Kadt, Mathieson e Wall, e Cazes). A essas e outras críticas (como as que Butcher faz também a Graburn e a MacCannell), Malcom Crick, por exemplo, já respondeu de forma bem mais eloquente, num texto célebre de $1989^{2}$ (que, sintomaticamente, Butcher não cita), deixando, para mim, fechada a discussão: resumindo Crick, o turismo não pode ser visto como um bode expiatório por parte dos cientistas sociais e isso implica: a) abandonar as visões românticas de preservação cultural como valor absoluto e imperialista de emocionalismo rousseauniano; b) entender a mudança provocada pelo turismo no quadro das mudanças sociais, culturais e económicas mais vastas; c) entender as mudanças e impactos em termos locais e contextualizados, fazendo interferir outros factores de dependência para além do turismo; d) atentar na focagem de outras relações potenciais de conflito e dependência internas, atomizando a dicotomia "ocidente / terceiro mundo"; e) reconhecer as participações locais nos processos turísticos; f) atentar nas mudanças culturais decorrentes dos processos turísticos nos dois sentidos; g) inserindo as análises relativas ao turismo internacional no quadro global do turismo (local e regional); h) comparando diferentes formas de turismo ao longo do tempo e em diferentes contextos; i) relativizando as críticas à "autenticidade encenada" porque, em última análise toda a cultura pode ser encenada; $\mathrm{j}$ ) relativizando, também as críticas ao caracter predatório e destruidor do turismo por forma a não negligenciar o seu potencial concomitante na preservação natural e cultural, viabilização económica e activação social. Tudo isto, se não era já óbvio para os antropólogos, ficou claro e escrito por Crick nos finais de 80 .

7 O livro de Butcher tem, pelo menos, esse efeito positivo (embora, para sermos justos, lhe reconheçamos mais alguns, como o de enunciar traços distintivos de alguns turistas e cooperantes que outros textos, ainda mais cáusticos, se limitam a designar como Third World groupies): o de devolver aos antropólogos a distorção da sua própria imagem, que talvez tenhamos que nos empenhar, de forma mais veemente, em contrariar. Não por brio ou corporativismo, mas para contribuir de forma mais efectiva para um debate mais sustentado relativo aos processos turísticos contemporâneos. Para isso, e respondendo a mais algumas críticas de Butcher, talvez seja importante que a Antropologia do Turismo se empenhe mais na divulgação das densas etnografias que tem vindo a produzir, não apenas em sítios de turismo alternativo, mas também em contextos de turismo de massa; talvez seja igualmente importante alargar ao máximo a vocação cosmopolita da Antropologia para contrariar uma certa miopia residual que continua a privilegiar muitas vezes a lupa mais culturalista para os destinos turísticos exóticos do "terceiro mundo», guardando lente mais sociológica para os destinos ocidentais. A sobreposição de lentes permite, em todos os contextos, uma melhor focagem. 
8 Em todo o caso, algumas emanações da obra de Butcher merecem, decididamente, ser controladas: nem os antropólogos podem ser confundidos com Sheldrake - o personagem literário de David Lodge em Férias no Paraíso; nem todos os turistas preocupados com a diferença cultural ou com o meio ambiente são cínicos e egoístas; nem, infelizmente, o turismo de massa pode alargar a todos (visitantes e visitados) o direito de fazer turismo, que mais não fosse porque - e isso, sim, é cinismo ignorar muitas rotas turísticas continuam a ser politicamente transitáveis apenas num dos seus sentidos.

\section{NOTAS}

1. ERIKSEN, T. H., 2001. "Between universalism and relativism: a critique of the UNESCO concept of culture", in COWAN, J. K., M.-B. Dembour, e R. A. Wilson (eds.), Culture [continua] and Rights. Anthropological Perspectives. Cambridge, Cambridge University Press, pp. 127-149.

2. CRICK, Malcolm, 1989, "Representations of international tourism in the social sciences: sun, sex, sights, savings, and servility". Ann. Rev. Anthropology, 18, pp. 307-44.

\section{AUTORES}

MARIA CARDEIRA DA SILVA

Departamento de Antropologia, FCSH-UNL 